\title{
Dihydroorotate Dehydrogenase Inhibitor ASLAN003
}

National Cancer Institute

\section{Source}

National Cancer Institute. Dihydroorotate Dehydrogenase Inhibitor ASLAN003. NCI

Thesaurus. Code C156777.

An orally available inhibitor of dihydroorotate dehydrogenase (DHODH), with potential antineoplastic activity. Upon administration, ASLAN003 specifically targets, binds to and prevents the activation of $\mathrm{DHODH}$, thereby preventing the fourth enzymatic step in de novo pyrimidine synthesis. This prevents uridine monophosphate (UMP) formation, DNA synthesis, cell division and cellular proliferation, causes reactive oxygen species (ROS) formation, enables differentiation and induces apoptosis in susceptible tumor cells. DHODH, a mitochondrial enzyme, catalyzes the conversion of dihydroorotate (DHO) to orotate in the endogenous synthesis of UMP. 